\title{
Agri-food supply chain coordination: the state-of-the-art and recent developments
}

\author{
Yuanita Handayati ${ }^{1}$ Togar M. Simatupang ${ }^{1}$ - Tomy Perdana ${ }^{2}$
}

Received: 4 July 2014/ Accepted: 23 September 2015/Published online: 8 October 2015

(C) The Author(s) 2015. This article is published with open access at Springerlink.com

\begin{abstract}
Researches on agri-food supply chain coordination have been gaining public attention due to their critical relevance to food availability, security, and safety. Still, the research focus is considerably in its early stage of development. This study was aimed at reviewing a holistic understanding on agri-food supply chain, particularly on issues related to coordination. This review was conducted by analyzing selected articles from peer-reviewed journals and proceedings. The articles are classified based on three important categories for researches on agri-food supply chain coordination, i.e., interdependencies, coordination mechanism, and methodology. Based on an analysis on the current state of research, a future research on agri-food supply chain coordination should be encouraged. Besides, the spectrum of coordination mechanism taken to deal with different levels of interdependencies and quality requirements is presented. The spectrum is useful for any member in an agriculture supply chain who is willing to coordinate its actions with other members for improving supply chain performance. Then, the results of analysis suggest that a further research on the adoption of value co-creation in the coordination process is required to deliver benefits not only for participating actors but also for end consumers.
\end{abstract}

Yuanita Handayati

yuanita@sbm-itb.ac.id

Togar M. Simatupang

togar@sbm-itb.ac.id

1 School of Business and Management, Bandung Institute of Technology, Bandung 40132, Indonesia

2 Faculty of Agriculture, Padjajaran University, Bandung 40132, Indonesia
Keywords Supply chain - Coordination - Agriculture . Fruits and vegetables $\cdot$ Literature review

\section{Introduction}

Agricultural products have an important role in the today's world economy. In particular, products derived from crops serve various customer demands, e.g., food and biofuel. Furthermore, the supply chain of agricultural products has become a hot issue because the public is increasingly aware of and concerned about the availability and safety of the foods being consumed [21]. At present, the consumers of agricultural products demand to have more information not only on the availability of a product in supermarkets but also on its farming, marketing, distribution, transportation, and processing activities [1]. Besides, consumer behavior as such involves issues related to public health, which is influenced by existing cases on contaminated products [20, 33]. For example, United States Centers for Disease Control and Prevention (US-CDC) has reported that Granny Smith and Gala apples have to be recalled due to bacterial contamination of Listeria monocytogenes at their packing facility. The phenomenon not only impacts one particular member of a supply chain, but also affects the entire supply chain reputation. Furthermore, if the increasing demand of an agriculture product is not supported by a good postharvest handling, agricultural waste would be a problem. Agricultural wastes are possible to produce from harvest wastes, i.e., stalks, straw, leaves, roots, and husks, and from perishable leftovers and unconsumed products. Those wastes might be potentially important resources if handled properly [34]. The wastes are convertible into heat, steam, charcoal, methanol, ethanol, or biodiesel. Coordination among supply chain members may utilize and reduce 
agriculture waste, and may have a significant impact in increasing farmers' revenue. Production cost could be reduced by utilizing buyers' resources (technical expertise transfer, specialized inputs, or credits to farmers). Therefore, interorganizational collaboration in a food supply chain should be increased due to: (1) the rise of food safety as a prominent societal issue; (2) raw materials in food distribution often closely resemble a final product; and (3) agriculture products would always to varying degrees be perishable goods [8].

The shifting behavior of agricultural consumers indicates that consumers have already known what they need and what value that they expect from a product they buy. Therefore, it is important for a firm to facilitate such a kind of value creation. Under certain circumstances, a firm has an opportunity to co-create values with its consumers. In a value co-creation, firm and consumers interact with each other, and they have opportunities to influence each other's process. Besides, Ballantyne and Varey [5] have mentioned that "value co-creations are dialogical processes of firm and customer that merge into one integrated process of coordinated actions, where both parties are active, learn together from each other and may directly influence each other," meaning that the coordination between actors in a supply chain, especially in an agricultural one, is the key if value co-creation is going to be implemented. The quality of interactions between actors in the value co-creation would affect overall supply chain performance [10, 30].

To improve the overall performance of an agricultural supply chain, any actor in the supply chain should be able to orchestrate its own actions; hence, each party could get proper benefits as the consequences of compromises made during the coordination [41, 42]. The term coordination refers to the ways of managing interdependencies between activities, which involve different entities working together toward a mutually defined goal [26]. Its other terms, i.e., cooperation, integration, and collaboration, also deal with the management of interdependencies between activities; however, in the context of supply chain, these alternative terms could be considered as an integral part of supply chain coordination [6].

Supply chain coordination is a way to redesign rights to decide, decision workflow, and resources among members in a supply chain to achieve higher profit margins, customer service performance improvement, and faster response time [24]. A supply chain that implements coordination is characterized by effective communication, information exchange, partnering, and performance monitoring [43]. In agriculture sector, coordination is critical because one characteristic feature of agri-chains is the dependency of value creation, particularly on features of seasonality, perishability, safety, and traceability factors throughout an end-to-end supply network [47, 51]. Bijman et al. [8] have noted that an increased interorganizational collaboration in food supply possibly occur due to: (1) the rise of food safety as a prominent societal issue; (2) raw materials in food distribution often closely resemble a final product; and (3) to varying degrees, foods would always be perishable goods.

Still, research on coordination-related issues in an agricultural supply chain is in its early development. The research mainly focuses on the coordination of different function within a supply chain, but may not cover coordination of the whole supply chain. A review by Ahumada and Villalobos [1], for example, has only attempted to deal with the production and distribution planning of agri-foods. The review has concluded that the use of integrated planning models in an agricultural supply chain is considerably limited. In fact, it likely occurs because an integrated model is arguably much more complex, but may offer greater benefits compared to its complexity. The study has mentioned that the development of production and distribution models for perishable crops is crucial for the benefits of either industry or final consumer. Moreover, a recent review by Shukla and Jharkharia [40] has only addressed major operational issues (e.g., demand forecasting, crop production planning, inventory management, and transportation-related issues) that may cause postharvest wastes in fruits, flowers, and vegetables. Besides, it has concluded that only little attention is given to losses due to inefficient harvesting. Tsolakis et al. [49], on the other hand, have discussed previous researches that have attempted to address issues related to decision-making in agri-food supply chains, for either crop- or non-crop-related chains, with a focus on mapping decision-making models into strategic, tactical and operational levels, and aim at indicating the lack of integrated supply chain design and planning. The review has mentioned that studies, which integrate production planning and inventory management or inventory with demand forecasting and transportation for agri-fresh produce, are considerably limited. There is virtually no review that has discussed a holistic view on agri-food supply chains with a particular attention to coordination-related issues. Therefore, the current review focuses on agri-food supply chain coordination. Vegetables and fruits are posited as the focus of review since these two agricultural products offer high value and require special attention in post-harvest handling and storage. In fact, highly perishable fruits and vegetables characteristics could increase the needs of famers and other members of a supply chain to coordinate harvest and delivery scheduling; hence, agricultural products would be received by consumers in as fresh as possible condition. The needs for post-harvest handling and storage must be implemented by all actors in the chain to obtain higher value and better quality of agricultural products being 
distributed. To lower production cost at farmers' side, coordination is also critically required for being implemented, particularly to find out any requirement for: (1) farmers to be able to have an efficient production and (2) buyers to transfer their resources for helping farmers in fulfilling their production needs.

The objective of these papers is to define the state-ofthe-art of supply chain coordination in agri-food chains and identify research gaps in this research area. This review aims at answering two questions: What kind of interdependencies has been developed in agri-food supply chain, and what kind of coordination mechanism has been taken to manage the interdependencies? These questions relate to such aspects as the coordination perspective might differ, which is affected by the background of each researcher, methodology taken in a research, difficulties and conflicts that usually appear in coordination, and coordination mechanism taken to counter the conflicts.

These papers are organized as follows. The classification of articles being reviewed is presented in Sect. 2. Section 3 explains selection processes on the articles. In Sect. 4, findings from the articles being reviewed are presented. Finally, Sect. 5 provides discussions on the findings, and Sect. 6 presents concluding review and gaps identified among the literature under observation, all of which should be addressed in future researches.

\section{Papers classification}

To discuss agri-food supply chain coordination, the basic concept of supply chain coordination and the specific characteristics of agriculture sector are combined. Selected literature is classified based on the particular content coverage and focus of each paper, i.e., the interdependencies in an agricultural supply chain, the coordination mechanism, and the methodology taken. Furthermore, interdependencies are analyzed by distinguishing interdependencies between activities and between actors. Coordination mechanisms taken to manage interdependencies are classified based on the scope of coordination mechanisms for a supply chain decision, i.e., strategic, tactical, and operational, including the effect of coordination mechanism on supply chain performance as shown in Fig. 1.

\subsection{Interdependencies}

The concept of interdependencies is critical in analyzing coordination. Malone and Crowston [26] have mentioned that coordination refers to managing interdependencies between activities. Besides, they have noted that when there are no interdependencies, there is nothing to coordinate. There are two perspectives of interdependencies taken in reviewing selected papers to investigate issues related to coordination, i.e., the perspective of interdependencies between activities and the perspective of interdependencies between actors.

It should be noted that many agricultural issues are in fact a series of linked processes or activities that involve multiple actors, e.g., supplying agricultural inputs, cultivating, harvesting, post-harvest handling, transporting, processing, marketing, and distributing [2]. It is important to determine interdependencies between the activities and among actors involved in agricultural supply chain coordination; hence, it is possible to understand whether the coordination is only focused on different functions within a supply chain, or focused on the whole supply chain.

\subsection{Coordination mechanism}

The mechanism is defined as a tool or way to manage interdependencies of activities between supply chain actors [3]. Supply chain performance is expected to improve through the implementation of coordination mechanisms. There are four different types of coordination mechanisms:

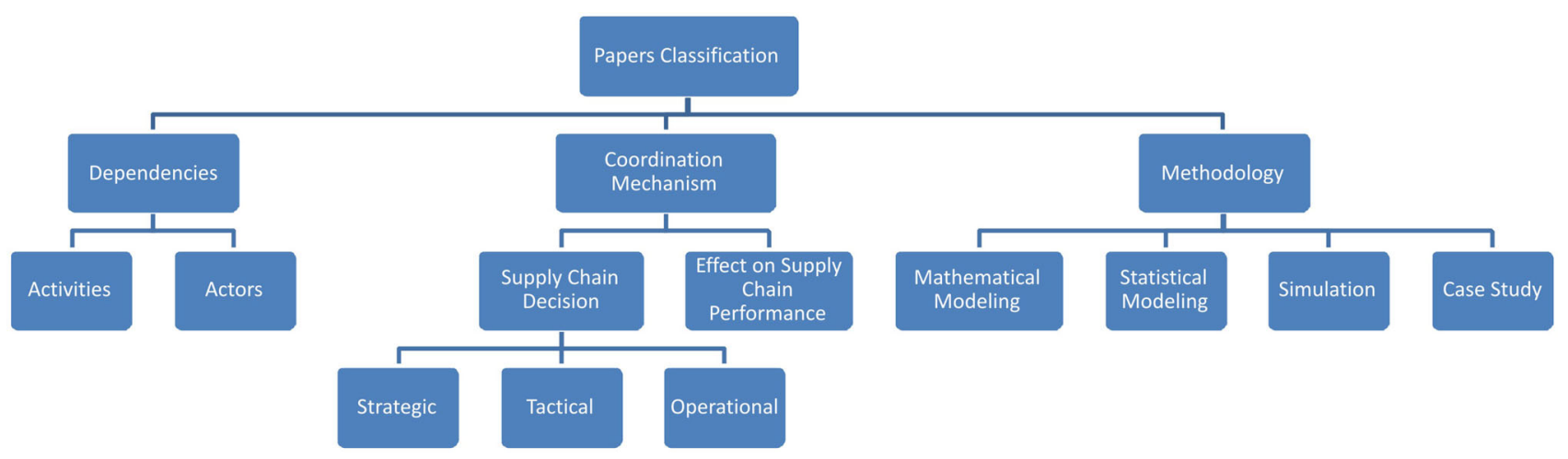

Fig. 1 Overview of the classification scheme 
- Supply chain contract: It is taken to manage supplierbuyer relationships and to manage risks in a supply chain. Several parameters are clearly specified in a contract, i.e., quantity, price, time, and quality, when a buyer places an order and when a supplier fulfills the order [3]. Other parameters possibly specified in a supply chain contract include an incentive alignment. Each decision that is made by actors in a supply chain has its own implications. Rewards or penalties given to particular actors according to the results of their decision are stated as incentives. The incentive alignment itself refers to a way to resolve the conflict of interest among actors in a supply chain by offering incentive schemes that may direct their behavior to conform to customers' focus and total profit [24, 41]. Auction, as an activity that facilitates sales of product between supplier and buyer, is possibly placed in a supply chain contract under "price discovery," a mechanism that gives a supplier transparency over product price [48].

- Information sharing: Lee [24] has mentioned that actors or decision-makers in a supply chain may share their information to avoid any distortion in the chain. Actors in a supply chain coordinate one another by sharing information related to demand, orders, inventory, etc. Several studies have shown that information sharing, supported by information technology (IT), may improve the performance of a supply chain $[11,13$, 16]. In supply chain coordination, IT is taken to facilitate information sharing among actors in a supply chain. In other words, coordination might be achieved by utilizing IT [27, 35]. The utilization may help actors in supply chains to develop an effective communication and improve supply chain operations.

- Joint decision-making: It may help actors in a supply chain to improve their performance. It is possible because a decision made by each actor may affect other actors' decisions, and a joint decision-making may avoid conflicts among the actors. For example, if an actor in a supply chain makes a decision related to a number of promotional activities, the decision may affect other actors' decisions related to production and replenishment processes. Joint decision-making is possibly implemented in replenishment [17], inventory [9], collaborative planning [4], and logistic synchronization [41].

- Collective learning: It may solve the problem of knowledge gap across organizations [36]. Collective learning is required to extend the capability of partners in accomplishing a continuous improvement [41].

In designing and managing an agri-food supply chain, the natural hierarchy of decision-making process is distinguished into strategic, tactical, and operational [1]. The coordination mechanism is one critical factor to consider in decision-making within a supply chain. Another important thing is the effect of the implementation of coordination mechanism to overall supply chain performance. It should be investigated to discover whether a mechanism taken is appropriate or not to manage interdependencies in agricultural supply chain coordination. Strategic supply chain coordination decisions are basically long term in terms of their scope and impact. Decisions define the direction of a supply chain. The strategic decisions involve all stakeholders who are willing to participate in agricultural supply chain networks.

Tsolakis [49] has presented an inclusive hierarchical decision-making framework for agriculture sector that is useful to analyze the existing literature. Tsolakis [49] has mentioned that strategic decisions in an agricultural supply chain are related to: the selection of farming technologies (e.g., determining capital requirements and expenditure for any farming equipment, developing cooperative schemes in the utilization of farming machinery, and adopting innovative farming applications), the development of an investment portfolio (e.g., determining investments in pivotal resources and infrastructure and assessing alternative financing options and optimization criteria), the fostering of supply chain partnering relationships (e.g., determining partners' roles, determining integration level, and establishing collaborative schemes as well as contract types), the configuration of supply chain networks (e.g., selecting optimum sourcing policies, developing efficient procurement channels, allocating processing/production facilities, allocating intermediary warehouses, designing transportation networks, designing retailers' networks, and selecting markets), the establishment of a performance measurement system (e.g., determining key performance indicators (KPIs), developing data-handling processes and mechanisms, selecting and developing measuring methods, and establishing stakeholders' collaboration structures), the assurance of sustainability (e.g., adopting CSR business practices, developing waste management policies, assessing system's sustainability, establishing carbon and water footprint control systems, adopting green farming practices, and designing sustainable supply chain networks), and the adoption of quality management policies (determining quality management system scope and determining quality management system scale).

Furthermore, the implementation of supply chain or firm strategy is related to tactical decision, while the day-to-day running of a business is related to operational decision. Besides, Tsolakis [49] has noted that the tactical and operational decisions in an agricultural supply chain are related to the planning of harvesting operations (e.g., 
scheduling planting as well as harvesting operations and resource management), the planning of logistics operations (e.g., fleet management, planning and scheduling of vehicle routing, identifying inventory management and control systems, and selecting packaging conditions as well as techniques), the support to food safety via transparency and traceability (e.g., promoting common governance mechanisms as well as organizational arrangements and adopting innovative tracking and tracing technologies).

\subsection{Methodology}

In this review, the selected literature is also distinguished based on particular methodology taken in each research. The methodologies are analyzed to conduct a measurement on the impact of coordination mechanisms on performance measures. The methodologies are categorized into mathematical modeling, statistical modeling, simulation, and case study. Mathematical modeling attempts to deal with mathematical concepts and language that may explain a system, including a study on the effects of different components, and to make predictions on behavioral issues. The second category, statistical modeling, usually refers to mathematical equations that relate one or more random variables and contains a set of assumptions based on observation data. Next, simulation attempts to imitate the operation of a real-world process or system over time. Then, case study is an in-depth investigation on an object of research. In a case study, every aspect of a research object is analyzed to seek the patterns and causes of behaviors. Methodologies taken in the literature being reviewed would be helpful to understand agricultural supply chain coordination from different perspectives of methodological point of view. It is to be highlighted that any methodology taken to solve a problem depends on the problem itself, data availability, computational resources, and the preferences of researcher in using the particular methodology [40].

\section{Papers selections}

A structured literature review is applied in selecting the papers. It is a literature review method that is particularly focused on a research question(s) to identify, appraise, select, and synthesize all research evidence relevant to the question(s) [31]. First, the search for relevant literature is conducted by using databases and citation indexes. Next, articles being identified are briefly scrutinized by checking the titles and abstracts against predetermined criteria for discovering their eligibility and relevance. The structured literature review in this study is focused on the topic of agri-food supply chain coordination.
To cover journals in operations management, agriculture, and those in adjacent fields, the Web of Science (WOS) database is taken. Web of Science is a most used and widely standard tool for generating citation data for research assessment purposes. WOS database is taken as a multidisciplinary citation resource due to its consistency [39]; broad subject-centered coverage [22]; controlled vocabulary and authority [39]; extensive date range that spans 40 years [39]; guaranteed quality and accuracy [29]; stability as the oldest resource [28]; and the ability for clients to personalize the services. Besides, it only includes refereed contents [28]. "Supply chain coordination in agriculture" is used as the primary key phrase to capture all literature related to the concept of coordination in agri-food supply chains. Date and journal filters are not applied.

The current structured literature review is taken to select 80 papers based on the topical relevance of each literature to supply chain coordination in agri-food, especially fruits and vegetables. Papers that do not contain the particular topic are therefore excluded. Based on title relevance and a fast screening on the papers' abstracts, 39 among the 80 papers are further selected because they contain specifically relevant topics. The other 41 papers are excluded, mainly because they focus on agricultural products other than fruits or vegetables. Next, the 39 papers are screened by reviewing the full papers. Then, forward and backward referencing of relevant and interesting papers is taken, which results in 16 papers to be further analyzed and classified.

\section{Findings}

Papers that meet the criteria of papers selection are analyzed and classified. As aforementioned, the selected 16 papers are classified into three categories, i.e., interdependencies, coordination mechanisms, and methodology. The analysis of each classification is explained as follows:

\subsection{Coordination based on its interdependencies}

The low number of selected papers in Table 1 shows that studies on agri-food supply chain coordination are rarely conducted. Besides, the publishing dates of the papers indicate that the studies in this area are relatively new and have just gained attention in the last recent years. However, there is a growing interest in conducting research on this topic. The growing interest is apparent because the selected papers are dominated by recently published ones.

Interdependencies among actors in agri-food supply chain based on their activities are affected by the final product(s) offered by the chain to end customers. For fruits and vegetables, two kinds of final products offered are 


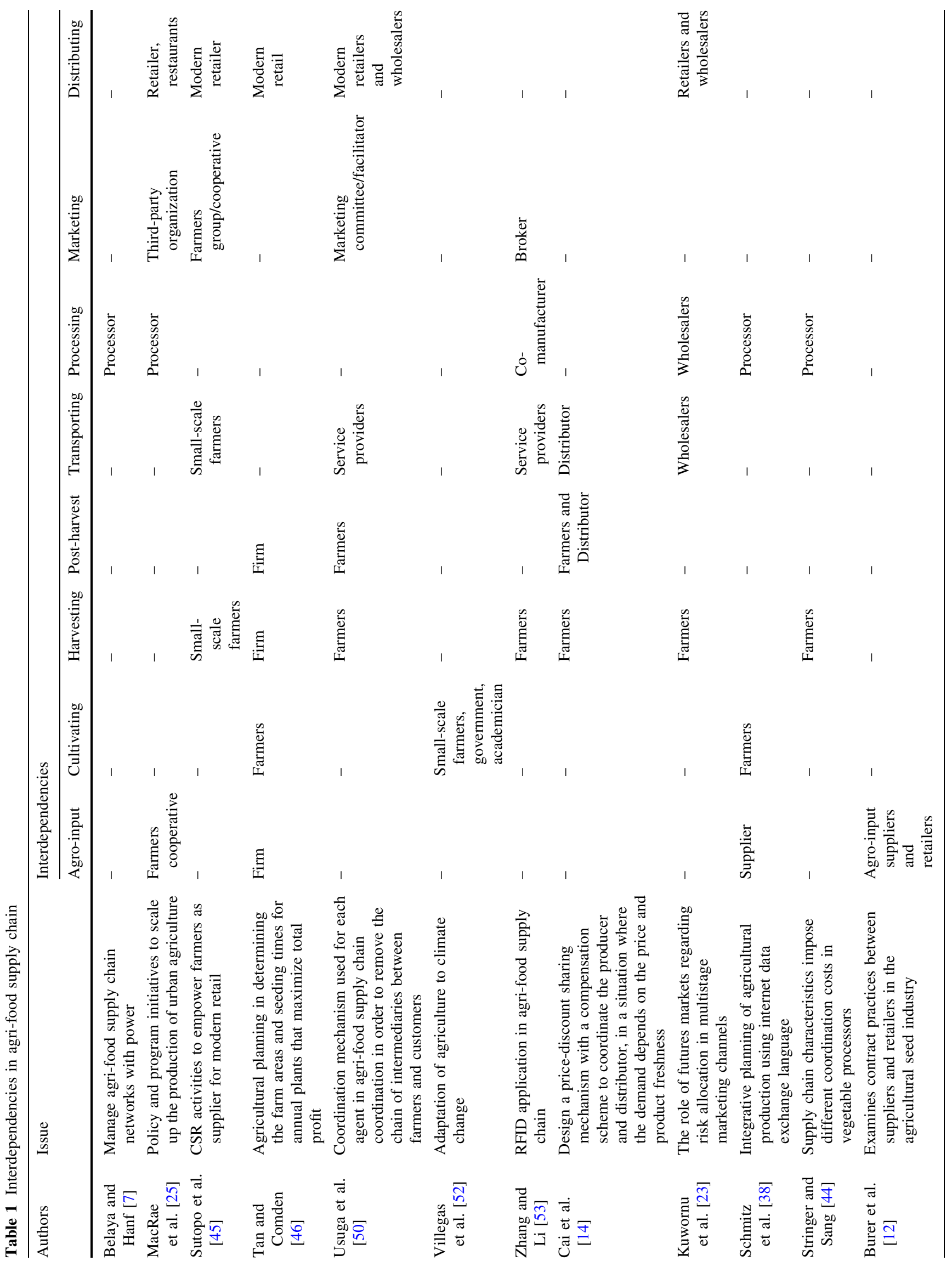




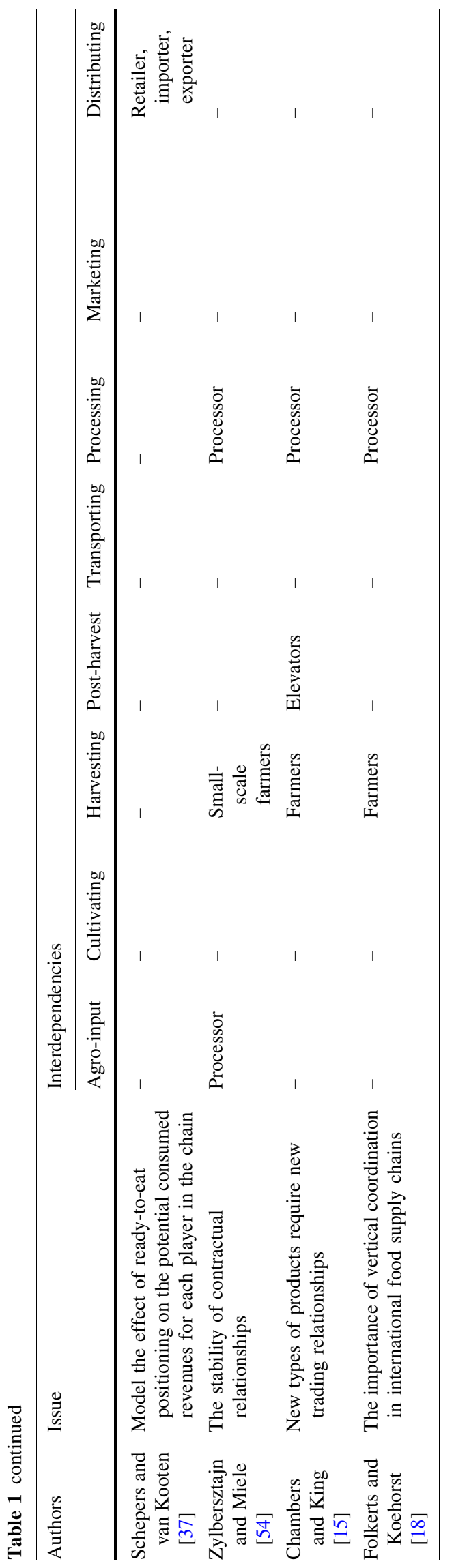

fresh produce and processed fruits and vegetables [18, 44]. Activity that distinguishes one another is processing, where fresh produce does not have to go through the process. The consequence is the shorter deterioration time of fresh produce compared to products that have gone through processing stage. On the contrary, the presence of processing activity may add to the cost of supply chain and the numbers of actors involved, making supply chain coordination more complex. Furthermore, issues discussed in agri-food supply chain coordination are varied. The dominating issues are supply chain contract $[12,54]$ and price mechanism $[14,37]$. Other issues related to coordination deal with climate change, the use of power to create coordination in an agri-food supply chain, coordination mechanisms to manage interdependencies, and activities or applications that require coordination.

The papers being reviewed illustrate all of important activities that should be considered in an agri-food supply chain. Activities ranging from agri-input supply to distribution and sales to end customers are discussed in these papers. However, none gives a holistic view of supply chain coordination in agri-food. All of them partially discuss coordination in agri-food supply chains. They only discuss two or three parts of the chains that need to be coordinated and do not pay attention to the entire chains. In fact, issue as such is related to all actors involved in the whole chain. Maintaining the relationship or coordination between actors is hence complex, because each actor has its own objectives or goals. Due to their limited focus and coverage, the papers do not consider dynamic relationships among actors in their models.

Another finding from the review is that coordination in agri-food supply chain is in fact dominated by the coordination between farmers and processors. It suggests that studies on the coordination of processed fruits and vegetables products have been more widely studied than the coordination of fresh produce. Coordination has become very important when fresh produce is associated with food safety. Since fresh produce does not require any further processing, it has a shorter deterioration time and is more easily contaminated. Furthermore, there is a need for researches on methods to help customers track and trace fresh produce being consumed, so that food safety is improved [53]. The survey suggests the use of radio frequency identification (RFID) as a way to achieve more accurate product identification. The technology helps actors in a supply chain share their data to one another.

Furthermore, a larger number of the reviewed papers discuss modern channels in their supply chain than those discussing traditional channels. It indicates that supply chain associated with modern channels requires more coordination than those associated with traditional ones. It occurs because in modern channels a higher attention is 
supposedly addressed to specification, availability and sustainability [45]. To meet these requirements, modern channels require supply chain actors to coordinate with one another. In addition, a study conducted by Sutopo et al. [45] has attempted to investigate coordination between farmers and modern retailers in handling deteriorated products in corporate social responsibility (CSR) activities. The CSR activities of modern channels are aimed at educating farmers to enhance their business skills and to reduce the impact of deterioration. In modern channels, therefore, product specifications, delivery terms, and internal business requirements are possible to achieve.

\subsection{Coordination mechanism taken in managing interdependencies}

Agri-food supply chain coordination is achieved by applying coordination mechanisms. Supply chain contract is the most common coordination mechanism taken in agrifood supply chains. Contracts are taken to coordinate supply chain members to have better supplier and buyer relationship and risk management. The contracts specify parameters that need to be considered by farmers for fulfilling buyers' demand, i.e., required area of farmland, required number of workers, the types of vegetables to grow, required agri-inputs such as fertilizer and seed, quality standards, delivery dates, financial risk allocations, bonuses and penalties, incentive alignments, clear targets, and result expectations.

A supply chain contract is commonly taken when coordination in agri-food supply chain only involves two actors. A study conducted by Kuwornu et al. [23] has examined contract supply arrangements among farmers, food processors, and retailers. The study attempts to assess interactions among farmers, food processors, and retailers by looking at contracts as well as assessing the impacts of incentives, coordination costs, and risk strategies on interaction. The study is conducted on the supply chain of Dutch potatoes. It indicates that the increase in incentives for producers and wholesalers would significantly decrease coordination costs in the marketing channel.

It is interesting to note that a research conducted by Chambers and King [15] has found that supply chain contract is not effective in maintaining the relationship between actors regarding new types of products. In contrast, other approaches, e.g., quality monitoring, certification-making procedures, and reputation, are found to be highly important. The condition applies when quality uncertainty has been a key problem, and contract enforcement is difficult due to expensive monitoring.

Furthermore, the Belaya and Henrich's [7] work also describes the use of power as a tool in managing supply chain coordination in agri-food. It is rather critical than other tools such as information sharing, joint decision-making, supply chain contracts, and collective learning. In particular, the study is aimed at finding the role of power in managing supply chain networks and its effects on coordination. The authors attempts to categorize power into six types and applies semistructured in-depth expert interviews with processing companies under investigation to develop a special ranking system for the use of each type of power. Then, the study shows that behavioral aspect is also an important aspect for being considered in a coordination process.

The other tools of coordination mechanism, i.e., information sharing, joint decision-making, and collective learning, are also taken to promote a harmonious relationship and to solve conflicts between actors in an agrifood supply chain, as discussed by Sutopo et al. [45], Usuga et al. [50], Villegas et al. [52], and Zylbersztajn and Miele [54].

Several authors have identified that more than one type of coordination mechanism might be taken to maintain coordination within a supply chain of agri-foods [50, 54]. The authors argue that more than one coordination mechanisms could be required because agri-food supply chain is a multistage activity and may act as enabling activities that involve more than two actors with different objectives and characteristics.

The effects on supply chain performance, when a coordination mechanism is being implemented, are varied, e.g., cost reduction, profit increase, quality improvement, higher productivity, food safety improvement, real knowledge basis construction, and long-term relationship maintenance. However, not all reviewed papers show how the effect is measured. Most of these papers only look at the effects of a coordination mechanism that has been successfully implemented in a particular case and assume that the same effects would occur if the same coordination mechanism is applied to another case.

The implementation of decision-making level of coordination mechanism varies in strategic, tactical, and operational levels. As Table 2 shows coordination mechanism is dominated by the application of supply chain contracts, usually relating to tactical and operational decisions [12, $23,44,46,50,54]$. In contrast, the supply chain contract for a strategic level receives little attention. Only one paper utilizes supply chain contracts or agreements in their supply chain to maintain its long-term relationship [18]. The paper suggests that it is necessary to make agreements among supply chain members for gaining confidence of other supply chain members and for having clear targets and expectation about the results of a long-term relationship. On the other hand, other coordination mechanisms are dominated by the implementation at operational level. Then, many short-term decisions related to the improvement in quality agri-food products must also be addressed. 
Table 2 Coordination mechanism in an agri-food supply chain

\begin{tabular}{|c|c|c|c|c|c|c|}
\hline \multirow[t]{2}{*}{ Authors, year } & \multicolumn{5}{|c|}{ Coordination mechanism } & \multirow[t]{2}{*}{ Effect on SC performance } \\
\hline & $\begin{array}{l}\text { Information } \\
\text { sharing }\end{array}$ & $\begin{array}{l}\text { Joint } \\
\text { decision- } \\
\text { making }\end{array}$ & $\begin{array}{l}\text { Supply } \\
\text { chain } \\
\text { contracts }\end{array}$ & $\begin{array}{l}\text { Collective } \\
\text { learning }\end{array}$ & Other & \\
\hline $\begin{array}{l}\text { Belaya and } \\
\text { Hanf [7] }\end{array}$ & - & - & - & - & Power & - \\
\hline $\begin{array}{l}\text { MacRae et al. } \\
\text { [25] }\end{array}$ & - & Strategic & - & - & & $\begin{array}{l}\text { Achieve a certain target of fresh } \\
\text { vegetable production }\end{array}$ \\
\hline $\begin{array}{l}\text { Sutopo et al. } \\
\text { [45] }\end{array}$ & - & Strategic & - & - & & Quality improvement \\
\hline $\begin{array}{l}\text { Tan and } \\
\text { Comden } \\
{[46]}\end{array}$ & - & - & Tactical & - & & Maximize firm's total profit \\
\hline $\begin{array}{l}\text { Usuga et al. } \\
\text { [50] }\end{array}$ & Operational & Operational & Operational & - & & $\begin{array}{l}\text { Inventory cost reduction, cost } \\
\text { saving, service level } \\
\text { improvement, order cycle time } \\
\text { reduction, increase customer } \\
\text { service quality, promote quality } \\
\text { of deliveries, reduce the risk of } \\
\text { errors in the distribution }\end{array}$ \\
\hline $\begin{array}{l}\text { Villegas et al. } \\
\text { [52] }\end{array}$ & Strategic & - & - & - & & $\begin{array}{l}\text { Adequate to produce a national } \\
\text { adaptation pathway }\end{array}$ \\
\hline $\begin{array}{l}\text { Zhang and } \mathrm{Li} \\
\text { [53] }\end{array}$ & $\begin{array}{l}\text { Tactical } \\
\text { operational }\end{array}$ & - & - & - & & - \\
\hline Cai et al. [14] & - & $\begin{array}{l}\text { Tactical } \\
\text { operational }\end{array}$ & - & - & & $\begin{array}{l}\text { Optimize the total profit of } \\
\text { producer and distributor }\end{array}$ \\
\hline $\begin{array}{l}\text { Kuwornu } \\
\text { et al. [23] }\end{array}$ & - & - & Tactical & - & & Increase profit \\
\hline $\begin{array}{l}\text { Schmitz et al. } \\
\text { [38] }\end{array}$ & Operational & - & - & - & & Build real knowledge bases \\
\hline $\begin{array}{l}\text { Stringer and } \\
\text { Sang [44] }\end{array}$ & - & - & Operational & - & & Reduce cost \\
\hline $\begin{array}{l}\text { Burer et al. } \\
{[12]}\end{array}$ & - & - & Tactical & - & & Increase profit \\
\hline $\begin{array}{l}\text { Schepers and } \\
\text { van Kooten } \\
{[37]}\end{array}$ & - & $\begin{array}{l}\text { Tactical } \\
\text { operational }\end{array}$ & - & - & & Optimize the chain profit \\
\hline $\begin{array}{l}\text { Zylbersztajn } \\
\text { and Miele } \\
\text { [54] }\end{array}$ & - & - & $\begin{array}{l}\text { Tactical } \\
\text { operational }\end{array}$ & - & & Maintain long-term relationship \\
\hline $\begin{array}{l}\text { Chambers and } \\
\text { King [15] }\end{array}$ & - & - & - & $\begin{array}{l}\text { Tactical } \\
\text { operational }\end{array}$ & $\begin{array}{l}\text { Quality monitoring, } \\
\text { certification procedures, } \\
\text { and reputation }\end{array}$ & $\begin{array}{l}\text { Product quality improvement, } \\
\text { quality uncertainty reduction, } \\
\text { transaction cost reduction }\end{array}$ \\
\hline $\begin{array}{l}\text { Folkerts and } \\
\text { Koehorst } \\
{[18]}\end{array}$ & - & - & Strategic & - & & - \\
\hline
\end{tabular}

\subsection{Methodology taken in addressing interdependencies and assessing coordination mechanism}

The most common methodology taken to describe supply chain coordination in agri-food chains is the case study. Seven of 16 papers focus on particular case studies. In addition, case studies are often taken to describe the process of coordination that occurs in an agri-food supply chain. The approach may give an overview on the field but may hardly provide alternative solutions applicable for agri-food supply chain coordination.

In fact, researches on agri-food supply chain coordination are dominated by the use of mathematical modeling as 
Table 3 Methodology used in agri-food supply chain coordination

\begin{tabular}{llll}
\hline Authors, Year & Methodology & & \\
\cline { 2 - 4 } & Approach & Statistical & Simulation \\
\cline { 2 - 4 } & Mathematical & Partial least squares & - \\
\hline Belaya and Hanf [7] & - & - & - \\
MacRae et al. [25] & - & - & - \\
Sutopo et al. [45] & Mixed integer linear programming & - & - \\
Tan and Comden [46] & Mixed integer linear programming & - & - \\
Usuga et al. [50] & - & - & Global circulation models \\
Villegas et al. [52] & - & - & - \\
Zhang and Li [53] & - & - & - \\
Cai et al. [14] & Analytical & - & Case study \\
Kuwornu et al. [23] & - & - & Multiagent \\
Schmitz et al. [38] & - & - & - \\
Stringer and Sang [44] & - & Conjoint analysis & - \\
Burer et al. [12] & Analytical & - & - \\
Schepers and van Kooten [37] & - & - & Case study \\
Zylbersztajn and Miele [54] & - & Multiple regression & - \\
Chambers and King [15] & - & - & - \\
Folkerts and Koehorst [18] & - & - & - \\
\hline
\end{tabular}

a methodology to address interdependencies and assess coordination mechanism. Most of these analytical approaches utilize deterministic variables and cannot accommodate the specific characteristics of agricultural products. The papers that contain an analytical approach investigate the coordination between two supply chain actors [12, 14].

Then, simulation is a less preferred approach in agrifood supply chain coordination. There is only one work in which simulation approach is utilized [52]. Villegas et al. [52] have simulated and analyzed climate change impacts on agriculture and could finally propose a set of adaptation measures to be considered in determining the purpose of supply chain coordination in agri-food sector. However, simulation approach in the study is not taken to show the process of coordination that occurs between actors involved in the agri-food supply chain under investigation and do not provide an alternative coordination mechanism to manage supply chain coordination. The detail list of methodology taken in addressing interdependencies and assessing coordination mechanism is shown in Table 3.

\section{Discussion}

Interdependencies in agri-food supply chain require a clear definition to provide a complete description on the focus of coordination, including any actor involved in the coordination. The findings discovered in this literature review indicate a research gap that is potential for being taken to identify future researches required for studying agricultural supply chain coordination. In particular, potential researches in agricultural supply chain coordination include investigations on consumer requirements, behavioral aspects, and a combination of hard and soft approach taken as the research methodology. From the findings related to interdependencies, several analyses could be derived. Based on the interdependencies, one may determine whether or not a study is focused on coordination that involves the whole or only several stages in a supply chain. Interdependencies between stages may also determine the purpose or focus of coordination.

Furthermore, analyses on interdependencies from previous studies indicate actors who are involved and the role of each actor in the interdependencies within an agri-food supply chain. There are no papers that explain the characteristics of actors within agri-food supply chain in detail. Those characteristics are required to investigate any determining coordination mechanism taken in managing interdependencies. Folkerts and Koehorst [18] have shown that coordination between actors in agri-food supply chains varies and is highly dependent on historical and cultural aspects as well as on a regulatory environment. There is also clear evidence on opportunistic behavior, wherein individual actors would only work together as long as there are clear and tangible benefits. Therefore, a study on coordination process, particularly to analyze coordination in more detail, is necessary. 
Additional studies on small-scale farmers are also required since the characteristics of a supply chain and farmers' behavior may make agri-food supply chain more complex. Moreover, as aforementioned in the findings section, studies on supply chain coordination in agri-food sector with a particular focus on small-scale farmers have not yet been well developed. Therefore, there is a lot of opportunities to conduct in-depth studies on agri-food supply chain coordination that involves small-scale farmers. For instance, a study may focus on values in coordination that should be delivered by small-scale farmers to fulfill consumer requirements, e.g., the quality and availability of agricultural products required by consumers.

Furthermore, the findings indicate that studies in analyzing a coordination process in an agricultural supply chain still lag behind, particularly ones related to either operational level of modern marketing channel or smallscale farmers. The process of coordination requires a more insightful and more detailed description. The process itself is related to interdependencies between stages in an agricultural supply chain, e.g., the processing of agri-inputs, the distribution of agricultural products, and the delivery of products to customers. Either the behavior or the characteristics of each actor need to be considered when analyzing a coordination process. Besides, the specific characteristics of an agricultural product need to be considered in a coordination process to obtain a more realistic description on the real conditions and situation in agricultural supply chain coordination [40].

The purpose of maintaining interdependencies or coordination between actors requires a further identification. In today's highly competitive era, the purpose should be based on consumer requirements. The findings have indicated that there is no study on agricultural supply chain coordination that has attempted to consider consumer requirements. The consumer's role has already been shifted, e.g., from isolated to connected, from unaware to informed, and from passive to active [32]. As the consequence, in maintaining interdependencies, any activity performed by each actor should have values that may fulfill consumer requirements. It is achievable by adopting a value co-creation concept. In the concept, consumers act as key actors who have to be involved in the system to improve the overall performance of an agricultural supply chain.

Prahalad and Ramaswamy [32] have noted that the collaboration between a firm and its customers in implementing value co-creation may improve efficiencies and increase profits in a long run. The collaboration may begin with a market-based transaction, which requires a firm to work closely with its suppliers and key customers within a network. The next step in collaboration requires information sharing. In the step, a greater level of trust or incentive is needed. Next, tasks and modalities in the collaboration would be more complex in which they require a firm to assess collaborative capacities. Moreover, Bonney et al. [10] have suggested that a partnership between firms that develop co-innovation has more opportunities for innovation in process, product, or service through a continuous improvement in the activation of Research and Development (R\&D) and New Product Development (NPD) divisions. Besides, the study concludes that the R\&D and NPD of a firm should take consumer value into account rather than simply focus on what is feasible to implement by the firm.

Moreover, looking at the analysis on interdependencies in previous studies, coordination mechanisms are suggested to manage interdependencies between stages and between actors in an agricultural supply chain. Coordination mechanism is chosen based on activities to be managed and the characteristics of actors involved in a coordination process. Then, a chosen coordination mechanism is analyzed to make sure that it is the most suitable coordination mechanism that may improve the overall performance of an agricultural supply chain. Choosing and implementing the coordination mechanism have to consider behavioral aspects. In a decision-making process, rational behavior is not always referred. Most decisionmakers use heuristics, which may lead to a biased decision, in their decision-making process, contributing to the poor performance of an agricultural supply chain [19]. The development of a coordination process in an agricultural supply chain model is an immediate need not only for the benefit of the industry but also for the benefit of end consumers. The use of a combination between soft and hard approaches is required to explain a coordination process in an agricultural supply chain.

Methodologies taken in the papers being reviewed are dominated by the hard aspects of coordination, which focus on optimization and quantitative results. On the other hand, the soft aspect of coordination focusses on the details of coordination, e.g., what are the motivations of each member of an agricultural supply chain to coordinate with other members, what kind of interdependencies that occur between supply chain members so that a coordination is needed, how to analyze which coordination mechanism is suitable to the interdependencies, and what kind of conflicts that occur in the process of coordination. These soft aspects of coordination would result in a comprehensive qualitative result, which is important as a basis of knowledge before the hard aspects of coordination are analyzed.

As aforementioned by Malone and Crowston [26], different types or levels of interdependencies are useful for identifying coordination mechanism. Besides, some of the papers being reviewed have mentioned that the use of a coordination mechanism also depends on the level of 
Fig. 2 Spectrum of coordination mechanism based on the interdependencies of actors in agri-food supply chain to fulfill customer quality requirements

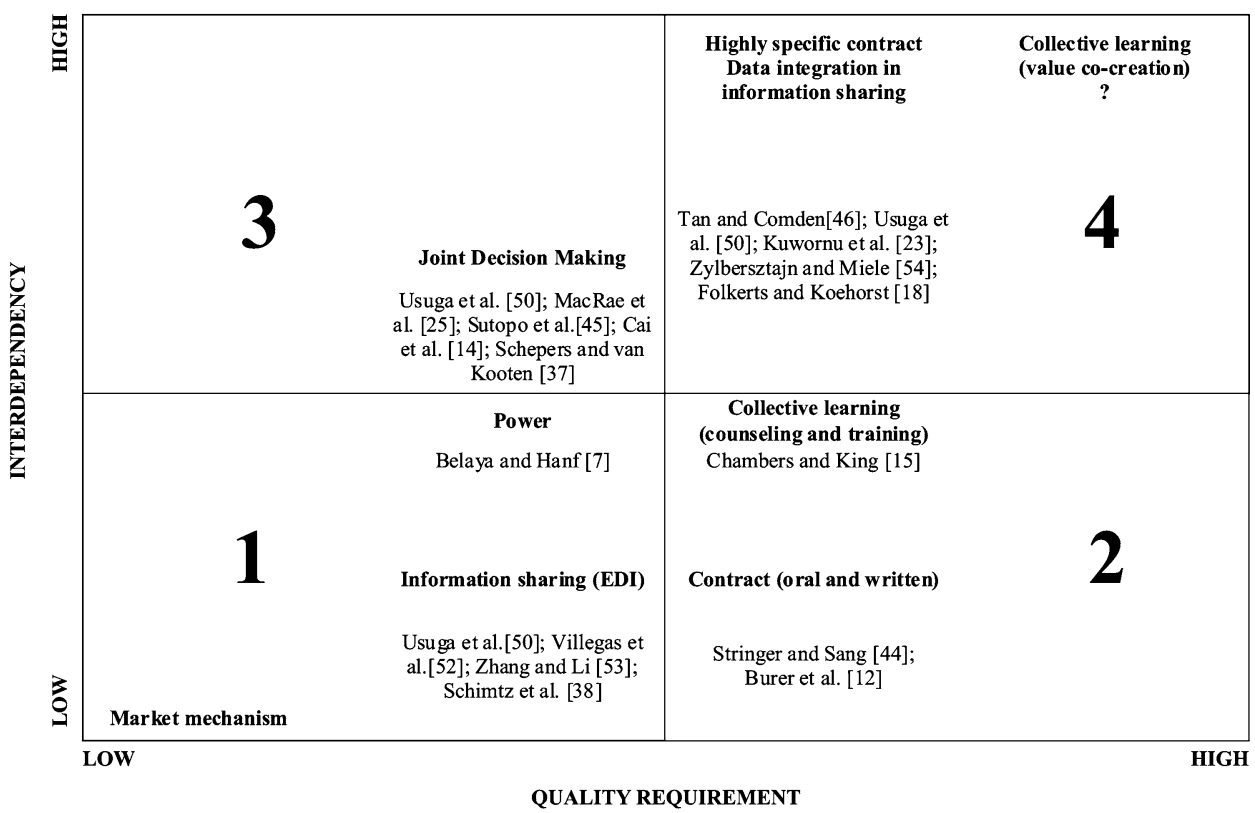

quality requirements demanded by customers. For example, Chambers and King's [15] and Stringer and Sang's [44] works have attempted to define different types of contracts based on the levels of product specifications. Looking at the explanation above, it is apparent that any coordination mechanism taken in agricultural supply chain coordination can be derived by considering two determinants, i.e., interdependencies and quality requirements. The level of interdependencies between actors indicates a different intensity of interaction and communication. The higher the interdependencies would indicate an increased level of communication. Besides, it indicates that an active interaction is required in the process of coordination within an agricultural supply chain. In addition, the level of interdependencies also shows how many actors in a supply chain need to integrate their agricultural activities, which span from agri-input, cultivation, harvesting, post-harvest, transportation, processing, and marketing, to distribution. Moreover, the level of quality requirement indicates the level of difficulties to achieve or fulfill customer requirements. A low level of quality requirement indicates willingness of customers to buy standard products. On the other hand, a high level of quality requirement indicates customers' willingness to buy agricultural products with a specific set of requirements according to the appearance of agri products, e.g., size, color, freshness, traceability, and safety from product contamination.

According to the level of interdependencies and the level of quality requirement, the papers can be mapped based on the coordination mechanism taken (see Fig. 2). Spectrum 1 shows the lowest level of interdependencies and the lowest level of quality requirement that do not need any specific coordination mechanism. In fact, it only requires market mechanism. Market mechanism illustrates the simplest transaction between a supplier and a buyer: When there is product, there is money, meaning that any product produced and offered would surely be sold in the market. Next spectrum shows the higher level of quality requirement but does not need higher interdependencies or interactions between actors or activities in an agri-food supply chain. This spectrum is manageable by utilizing information sharing as the coordination mechanism. However, information sharing in this spectrum only applies for basic information possibly exchanged using electronic data interchange. Some other papers mention power as a coordination mechanism that can be used for low interdependencies and a higher-quality requirement. The coordination mechanism is useful to implement the action plan of coordination.

Furthermore, the Spectrum 2 illustrates that for a higherquality requirement than the Spectrum 1 with low interdependencies, a simple contract can be used as the coordination mechanism. The simple contract usually applies orally or written, which only consists of quantity and quality demanded by a buyer, without any detailed requirement. In the same spectrum, a simple collective learning, i.e., counseling and training, can be implemented to deal with a higher-quality requirement and low interdependencies. A simple collective learning illustrates the need to fulfill certain quality requirements for a specific agricultural product with helps from others to bridge the knowledge gap of farmers in implementing good agricultural practices. Then, the Spectrum 3 illustrates the need for a joint decision-making as a coordination mechanism to 
deal with high interdependencies or high interaction and communication among actors in an agri-food supply chain; however, it may not always have to fulfill high-quality requirements for customers. The last spectrum, 4, shows high-quality requirements for being fulfilled by high interdependencies. Highly specific contract and information sharing for data integration can be used for condition as such. However, a higher specific quality requirement of agricultural products requires more interactions and interdependencies between actors in a supply chain, which can be accommodated by applying collective learning as a tool for value co-creation. After analyzing all selected papers, there are no papers that discuss the Spectrum 3, which implements value co-creation mechanism in agri-food supply chain coordination.

\section{Conclusions}

An assessment of the gaps in the existing literatures on agri-food supply chain coordination is presented in this paper. Previous studies on agriculture supply chain coordination have been surveyed and classified, and the needs for future researches have been identified. Studies analyzing coordination process in agri-food supply chains still lag behind, particularly when a supply chain is strongly associated with the operational level of modern marketing channels and small-scale farmers.

A holistic view on coordination in agri-food supply chain is required, particularly when it is focused on the process of coordination. Besides, the process should be explained deeper and in detail. A coordination process itself is related to interdependencies between stages in an agri-food supply chain, e.g., agri-input activities, agriproduct distributions and final delivery to end customers. Furthermore, the process should adopt value co-creation concept, and hence, any activity performed by actors in a supply chain would have values that meet the requirements of consumers. Then, actors and their characteristics need to be considered when analyzing a coordination process.

On the other hand, the specific characteristics of an agriproduct also need to be considered in a coordination process to develop a more realistic description on the real condition and situation in an agri-food supply chain. Looking from the viewpoint of interdependency, coordination mechanisms are chosen to manage interdependencies between stages and between actors in an agri-food supply chain. A coordination mechanism is chosen based on activities to be managed and the characteristics of actors involved in a coordination process. Then, the mechanism is analyzed further to make sure that it is the most suitable coordination mechanism for improving the overall performance of an agri-food supply chain. The development of appropriate coordination processes in agri-food supply chain models is clearly required, by which the result would benefit the industry and end consumers. Moreover, the spectrums of coordination mechanism may help practitioners in the agriculture sector to improve their supply chain performance by implementing a proper coordination.

Then, the soft aspects of coordination are potential for being analyzed in future researches to capture the detailed process of coordination, to analyze conflicts and barriers that occur in the process of coordination, and to implement coordination mechanisms to improve the performance of the whole supply chain. Moreover, the current practices of agriculture strongly focus on products, meaning that a stronger focus on delivering products to customers is required. The innovative capability of different stakeholders (members in a supply chain) is clearly required to provide customers with multiple new offerings. The members are supposed to make their customers aware that an involvement in value co-creation can surely increase their benefits.

Open Access This article is distributed under the terms of the Creative Commons Attribution 4.0 International License (http://crea tivecommons.org/licenses/by/4.0/), which permits unrestricted use, distribution, and reproduction in any medium, provided you give appropriate credit to the original author(s) and the source, provide a link to the Creative Commons license, and indicate if changes were made.

\section{References}

1. Ahumada O, Villalobos JR (2009) Application of planning models in the agri-food supply chain: a review. Eur J Oper Res 196(1):1-20. doi:10.1016/j.ejor.2008.02.014

2. Aramyan C, Ondersteijn O, van Kooten O, Lansink AO (2006) Performance indicators in agri-food production chains. In: Ondersteijn CJM, Wijnands JHM, Huirne RBM, van Kooten O (eds) Quantifying the agri-food supply chain. Springer, Netherland, pp 49-66

3. Arshinder KA, Deshmukh SG (2008) Supply chain coordination: perspective, empirical studies and research direction. Int J Prod Econ 115(2):316-335. doi:10.1016/j.ijpe.2008.05.011

4. Aviv Y (2001) The effect of collaborative forecasting on supply chain performance. Manag Sci 47(10):1326-1343. doi:10.1287/ mnsc.47.10.1326.10260

5. Ballantyne D, Varey R (2008) The service-dominant logic and the future of marketing. J Acad Mark Sci 36(1):11-14. doi:10. 1007/s11747-007-0075-8

6. Barbarosolu G (2000) An integrated supplier-buyer model for improving supply chain coordination. Prod Plan Control 11(8):732-741. doi:10.1080/095372800750038337

7. Belaya V, Henrich J (2012) Managing Russian agri-food supply chain networks with power. J Chain Netw Chain 12(3):215-230. doi: $10.3920 / J C N S 2012 . x 217$

8. Bijman J, Omta SWF, Trienkens JH, Wijnands JHM, Wubben EFM (2006) International agri-food chains and networks. Management and organization. Wageningen Academic Publishers, Wagengingen

9. Boctor FF, Laporte G, Renand J (2004) Models and algorithms for the dynamic joint replenishment problem. Int J Prod Res 42(13):2667-2678. doi:10.1080/00207540410001671660 
10. Bonney L, Clark R, Collins R, Fearne A (2007) From serendipity to sustainable competitive advantage: insights from Houston's Farm and their journey of co-innovation. Supply Chain Manag Int J 12(6):395-399. doi:10.1108/13598540710826326

11. Bourland KE, Powell SG, Pyke DF (1996) Exploiting timely demand information to reduce inventories. Eur $\mathrm{J}$ Oper Res 92(2):239-253. doi:10.1016/0377-2217(95)00136-0

12. Burer S, Jones PC, Lowe TJ (2008) Coordinating the supply chain in the agricultural seed industry. Eur $\mathbf{J}$ Oper Res 185(7):354-377. doi:10.1016/j.ejor.2006.12.015

13. Cachon GP, Fisher M (2000) Supply chain inventory management and the value of shared information. Manag Sci 46(8):1032-1048. doi:10.1287/mnsc.46.8.1032.12029

14. Cai X, Chen J, Xu X (2009) Optimization and coordination of fresh product supply chains with freshness-keeping effort. Prod Oper Manag 19(3):261-278. doi:10.1111/j.1937-5956.2009.01096.x

15. Chambers W, King RP (2002) Changing agricultural markets: industrialization and vertical integration in the dry edible bean industry. Rev Agric Econ 24(2):495-511. doi:10.2307/1349774

16. Chen F, Drezner Z, Ryan JK, Levi DS (2000) Quantifying the bullwhip effect in a simple supply chain: the impact of forecasting, lead times, and information. Manag Sci 46(3):436-443. doi: $10.1287 / \mathrm{mnsc} .46 .3 .436 .12069$

17. Chen TH, Chen JM (2005) Optimizing supply chain collaboration based on joint replenishment and channel coordination. Transp Res Part E 41(4):261-285. doi:10.1016/j.tre.2004.06.003

18. Folkerts H, Koehorst H (1997) Challenges in international food supply chain: vertical co-ordination in the European business and food industries. Supply Chain Manag 2(1):11-14. doi:10.1108/ 13598549710156312

19. Gino F, Pisano G (2008) Toward a theory of behavioral operations. Manuf Oper Manag 10(4):676-691. doi:10.1287/msom. 1070.0205

20. Grunert KG (2005) Food quality and safety: consumer perception and demand. Eur Rev Agric Econ 32(3):369-391. doi:10.1093/ eurrag/jbi011

21. Hastuti EY (2007) The influence of agribusiness system applied to vegetables farmers income improvement in Boyolali regency. Dissertation, Diponegoro University

22. http://www.thomsonreuters.com/products_services/science/academic

23. Kuwornu JKM, Kuiper WE, Pennings JME (2009) Agency problem and hedging in agri-food chains: model and application. J Mark Channels 16:265-289. doi:10.1080/10466690902934557

24. Lee HL (2000) Creating value through supply chain integration. Supply Chain Manag Rev 4(4):30-36

25. MacRae R, Nasr J, Kuhns J, Baker L, Christianson R, Danyluk M, Snider A, Gallant E, Vinish PK, Michalak M, Oswald J, Patel Wekerle G (2012) Could Toronto provide $10 \%$ of its fresh vegetable requirements from within its own boundaries? Part II, policy supports and program design. J Agric Food Syst Community Dev 2(2):147-169. doi:10.5304/jafscd.2012.022.002

26. Malone T, Crowston K (1994) The interdisciplinary study of coordination. ACM Comput Surv 26(1):87-119. doi:10.1145/ 174666.174668

27. McAfee A (2000) The impact of enterprise information technology adoption on operational performance: an empirical investigation. Prod Oper Manag 11(1):33-53. doi:10.1111/j. 1937-5956.2002.tb00183.x

28. Norris M, Oppenheim C (2007) Comparing alternatives to the Web of Science for coverage of the social sciences' literature. J Informetr 1(2):161-169. doi:10.1016/j.joi.2006.12.001

29. Mikki S (2009) Comparing google scholar and ISI web of science for the earth sciences. Scientometrics 82(2):321-331. doi:10. 1007/s11192-009-0038-6

30. Pedrosa A (2009) Motivating stakeholders for co-created innovation. Technol Innov Manag Rev 1(4):35-39
31. Petticrew MA, Roberts H (2006) Systematic reviews in the social sciences. Blackwell, Oxford

32. Prahalad CK, Ramaswamy V (2004) Co-creating unique value with customers. Strategy Leadersh 32(3):4-9. doi:10.1108/ 10878570410699249

33. Röhr A, Lüddecke A, Drusch S, Müller MJ, Alvensleben RV (2005) Food quality and safety-consumer perception and public health concern. Food Control 16(8):49-55. doi:10.1016/j.food cont.2004.06.001

34. Sabiiti EN, Bareeba F, Sporndly E, Tenywa JS, Ledin S, Ottabong E, Kyamanywa S, Ekbom B, Mugisha J, Drake L (2005) Urban market garbage. A resource for sustainable crop/livestock production system and the environment in Uganda. International conference, wastes - the social context. Edmonton, Canada

35. Sanders NR (2008) Pattern of information technology use: the impact on buyer-supplier coordination and performance. J Oper Manag 26(3):349-367. doi:10.1016/j.jom.2007.07.003

36. Sawhney M, Prandelli E (2000) Communities of creation: managing distributed innovation in turbulent markets. Calif Manag Rev 42(4):24-54. doi:10.2307/41166052

37. Schepers H, van Kooten O (2006) Profitability of ready to eat strategies: towards model-assisted negotiation in a fresh-produce chain. In: Ondersteijn CJM, Wijnands JHM, Huirne RBM, van Kooten O (eds) Quantifying the agri-food supply chain. Springer, Netherlands, pp 117-132

38. Schmitz M, Martini D, Kunisch M, Mosinger HJ (2009) Enabling standardized, platform-independent internet data exchange in farm management information systems. Springer, Heidelberg

39. Schroeder R (2007) Pointing users toward citation searching: using Google Scholar and Web of Science. Libr Acad 7(2):243-248. doi:10.1353/pla.2007.0022

40. Shukla M, Jharkharia S (2012) Agri-fresh produce supply chain management: a state-of-the-art literature review. Int J Oper Prod Manag 33(2):1-61. doi:10.1108/01443571311295608

41. Simatupang TM, Sridharan R (2000) The collaborative supply chain. Int J Logist Manag 13(1):15-30. doi:10.1108/ 09574090210806333

42. Sirias D, Mehra S (2005) Quantity discount versus lead timedependent discount in an inter-organizational supply chain. Int $\mathrm{J}$ Prod Res 43(16):3481-3496. doi:10.1080/00207540500117995

43. Stank TP, Crum MR, Arango M (1999) Benefits of interfirm coordination in food industry in food industry in supply chain. J Bus Logist 20(2):21-41

44. Stringer R, Sang S (2009) Producers, processors, and procurement decisions: the case of vegetable supply chains in china. World Dev 37(11):1773-17801. doi:10.1016/j.worlddev.2008.08. 027

45. Sutopo W, Hisjam M, Yuniaristanto (2012) An agri-food supply chain model to empower farmers as supplier for modern retailer using corporate social responsibility activities on deteriorated product. Int MultiConf Eng Comput Sci II 86:189-202. doi:10. 1007/978-94-007-5651-9_14

46. Tan B, Cömden N (2012) Agricultural planning of annual plants under demand, maturation, harvest, and yield risk. Eur J Oper Res 220(2):539-549. doi:10.1016/j.ejor.2012.02.005

47. Taylor DH, Fearne A (2006) Towards a framework for improvement in the management of demand in agri-food supply chain. Supply Chain Manag Int J 11(5):379-384. doi:10.1108/ 13598540610682381

48. Tourte L, Gaskell M (2004) Horticultural auction markets: linking small farms with consumer demand. Renew Agric Food Syst 19(3):129-134. doi:10.1079/RAFS200475

49. Tsolakis NK, Keramydas CA, Toka AK, Aidonis DA, Iakovau ET (2014) Agrifood supply chain management: acomprehensive hierechical decision-making framework and a critical taxonomy. 
Biosyst Eng 120:47-64. doi:10.1016/j.biosystemseng.2013.10. 014

50. Usuga MLR, Jaimes WA, Suarez OE (2012) Coordination on agrifood supply chain. World Acad Sci Eng Technol 6(11): 357-361

51. Van Der Vorst JGAJ, Beulens AJM, Van Beek P (2000) Modelling and simulating multi-echelon food systems. Eur J Oper Res 122(2):354-366. doi:10.1016/S0377-2217(99)00238-6

52. Villegas JR, Salazar M, Jarvis A, Racines CEN (2012) A way forward on adaptation to climate change in Colombian agriculture: perspectives towards 2050. Clim Change 115(3):611-628. doi:10.1007/s10584-012-0500-y

53. Zhang M, Li P (2012) RFID application strategy in agri-food supply chain based on safety and benefit analysis. Int Conf Solid State Devices Mater Sci 25:636-642. doi:10.1016/j.phpro.2012. 03.137

54. Zylbersztajn D, Miele M (2005) Stability of contracts in the Brazliian wine industry. Revista de Economia e Sociologia Rural. 43(2):353-371. doi:10.1590/S0103-20032005000200008 